\title{
Social and environmental risk factors for the accidental drowning of children under five in China
}

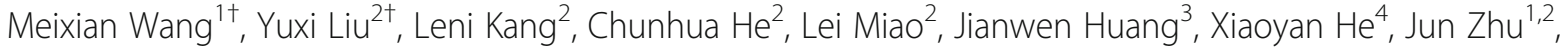
Juan Liang ${ }^{2}$, Qi Li ${ }^{2}$, Yanping Wang ${ }^{2 *+}$ and Hanmin Liu', ${ }^{1,5^{*+}}$

\begin{abstract}
Background: Accidental drowning of children under five is a serious problem in China. The present study analyzed data on environmental and sociodemographic factors and on primary caregivers of drowned children to understand factors that may contribute to this problem.

Methods: The present study collected information on 563 cases of drowning in children under five from October 1, 2015, to September 30, 2016, in 334 sampling districts in China. Primary caregivers were interviewed individually using the Drowning Mortality among Children under 5 Questionnaire.

Results: Most drowned children under 5 years old were boys, and $71.6 \%$ lived within $100 \mathrm{~m}$ of a body of water. The drownings primarily occurred in ponds, canals, rivers, and wells, and over $90 \%$ of these water bodies had no safety measures. There were $28.1 \%$ of primary caregivers who did not provide full-time care for the children, and 83.1\% of them had no knowledge of first aid skills for drowning.

Conclusion: Encouraging kindergarten enrollment and providing safety education for children may reduce drowning in children under 5 years of age. Public water body protection measures should be strengthened to prevent children from drowning. Encouraging primary caregivers to care full-time for the children and learning first aid skills for drowning may also help reduce fatalities.
\end{abstract}

Keywords: Accidental drowning, Risk factors, Children, China

\section{Background}

Drowning is a serious contributor to mortality and disability. With nearly 372,000 deaths reportedly due to drowning each year worldwide, it is a leading cause of child mortality [1]. Drowning that does not end in death

\footnotetext{
*Correspondence: wyxyanping@163.com; hanmin@vip.163.com

${ }^{+}$Meixian Wang, Yuxi Liu, Yanping Wang and Hanmin Liu contributed equally to this work.

${ }^{2}$ National Office for Maternal and Child Health Surveillance of China, West China Second University Hospital, Sichuan University, Chengdu, Sichuan, China 'Key Laboratory of Birth Defects and Related Diseases of Women and Children (Sichuan University), Ministry of Education, West China Second University Hospital, Chengdu, China

Full list of author information is available at the end of the article
}

may lead to cognitive difficulties, hypoxic-ischemic brain injury, cardiac abnormalities, and adult respiratory disease syndrome later in life [2-4]. Although the mortality rate due to drowning is decreasing [5], the associated economic burden remains significant. For example, the combined effects of fatal and nonfatal drowning in 2017-2018 cost 1.47 billion AUD (over 7.1 billion Chinese renminbi) [6].

Drowning is the main cause of accidental deaths in children worldwide under 5 years of age [7]. As the world's largest developing country, China has a large population and abundant water bodies in most regions, and child drowning is also a major problem in China. In

(C) The Author(s). 2020 Open Access This article is licensed under a Creative Commons Attribution 4.0 International License, which permits use, sharing, adaptation, distribution and reproduction in any medium or format, as long as you give appropriate credit to the original author(s) and the source, provide a link to the Creative Commons licence, and indicate if changes were made. The images or other third party material in this article are included in the article's Creative Commons licence, unless indicated otherwise in a credit line to the material. If material is not included in the article's Creative Commons licence and your intended use is not permitted by statutory regulation or exceeds the permitted use, you will need to obtain permission directly from the copyright holder. To view a copy of this licence, visit http://creativecommons.org/licenses/by/4.0/ The Creative Commons Public Domain Dedication waiver (http://creativecommons.org/publicdomain/zero/1.0/) applies to the data made available in this article, unless otherwise stated in a credit line to the data. 
response, China has made many efforts to reduce the accidental drowning mortality rate in children, and relevant health education is actively performed at the national level. The National Health Commission of the People's Republic of China released the "Chinese citizens' health literacy: basic knowledge and skills guidelines in 2015", which called for the strengthening of child supervision and education to prevent children from approaching dangerous waters [8]. Some regional governments issued a number of safety documents, including "Notice on the prevention of drowning in adolescents and children in 2019" and "Notice on doing a good job in preventing drowning of adolescents and children in 2019" [9, 10]. The Education Bureaus of many provinces also issued notices on the prevention of drowning, such as the "Notification of education on swimming safety for primary and middle school students" and the "Prohibition of bathing in rivers during summer vacation" [11].

Despite these and other preventative efforts, drowning remains an important cause of unintentional death in Chinese children [12-17]. Because of the absence of national-level data, we performed individual interviews with primary caregivers of drowned children from various parts of the country (registered in the National Maternal and Child Health Surveillance System) to elucidate the characteristics and risk factors of drowning deaths in children under five. The surveillance districts were evenly distributed in 31 provinces (autonomous regions and municipalities) of China to ensure representation of the entire country and different regions. Our results may help improve preventive measures and provide recommendations to reduce drowning mortality in this vulnerable age group.

\section{Methods}

\section{Study subjects}

The survey covered all 334 districts in the National Maternal and Child Health Surveillance System (NMCHSS) and 31 provinces, autonomous regions, and municipalities of China. The surveillance subject included all children under 5 in local resident households, adoptive children, and children in nonlocal resident households whose mothers lived in the surveillance districts for more than 1 year. The NMCHSS helps the national and local provincial health management departments supervise and guide health surveillance. Further details about the NMCHSS are described elsewhere [18]. The survey time period was October 1, 2015, to September 30, 2016, and there were 563 of children under 5 years in surveillance districts who died from drowning and are included in the present survey. The research team participated in the research design, questionnaire design, and data collection. We were also responsible for descriptive analysis and reporting.

\section{Questionnaire}

Collected data were in the form of responses of primary caregivers or other family members to the Drowning Mortality among Children under 5 Questionnaire, which was designed by the Chinese National Health Commission and UNICEF to gain information on children under five who died due to drowning. The questionnaire contains four parts: basic information about children, caregivers and families, and the circumstances of the drowning. All respondents provided informed consent for their anonymized responses to be analyzed and published.

\section{Data collection and quality control}

A trained investigator in each district branch of the National Maternal and Child Health Surveillance System was responsible for the implementation and conduct of the survey, as well as for interviewee surveying, questionnaire completion, quality control of the data, and reporting of the results. The interviews with respondents were performed within 3 months after the child's death. At the beginning of the interview, the investigator read the questionnaire description and corresponding notes to the respondent and was allowed to call the person in charge at any time if he or she had any questions. The same investigator checked the completeness and reliability of the data after the interview. The completed questionnaires were submitted stepwise at the district, county, prefecture, city, and provincial levels of maternal and child health care centers to the National Office of Maternal and Child Health Surveillance.

\section{Statistical analysis}

EpiData (version 3.1, The EpiData Association, Odense, Denmark) was used to establish the database. The questionnaires were double entered with logic and consistency checks. Proportions were calculated to describe the main results. Data were analyzed using SPSS 22.0 (IBM, Armonk, NY, USA).

\section{Results \\ Sociodemographic variables associated with children under five who drowned in $\mathbf{3 3 4}$ districts in China Descriptive characteristics of drowned children}

The investigation included 563 children under 5 years who drowned in 334 counties in China. The proportion of male-to-female children who drowned was approximately 3:2 (348:214). Among these children, the $1 \sim$ and $2 \sim$ year age group children each represented over $30 \%$, and the $3 \sim$ year age group children were the next highest group at $17.6 \%$. Although 3 years was the age required to enroll in kindergarten, $55.2 \%$ of drowned 
children aged 3 years and over were not enrolled in kindergarten (See Fig. 1).

\section{Safety education and risky drowning behaviors of children} The investigation also collected the safety education status of children 1 year and older. The safety education included knowing places of frequent drowning, avoiding risky drowning behaviors, understanding how to save themselves after submersion in water, and understanding how to seek help when others drowning. However, only $20.7 \%$ of children received safety education. Since playing near bodies of water may increase the risk of drowning, the investigation also surveyed risky drowning behaviors in all children. The results suggested that 3.6\% of children always played near bodies of water, and $55.2 \%$ of children sometimes played near bodies of water. Moreover, $75.7 \%$ of children were playing near the body of water at the time of drowning, and $4.6 \%$ of children were playing in the body of water (See Table 1).

\section{Characteristics of caregivers of drowned children under five in China \\ Sociodemographics of primary caregivers}

We examined the primary caregivers for each of the 563 drowned children and found that most of them $(70.0 \%)$ were aged between 20 and 40 years old, and $21.0 \%$ were over 50 years old. Mothers composed a significant proportion of primary caregivers $(70.7 \%)$, and approximately one-quarter $(24.2 \%)$ of primary caregivers were grandparents. Only $2.0 \%$ of caregivers held some form of a college degree. The vast majority (90.2\%) attained a junior high school education or less. The definition of drowning first aid skills in this investigation was that the primary caregivers could notice signs of drowning and complete first aid for drowning, which included the removal of foreign bodies in the respiratory tract, helping to extract fluid, and cardiopulmonary resuscitation. Drowning first aid skills were mostly lacking, and $83.1 \%$ of primary caregivers reported having received no training.

\section{Activities of primary caregivers at the time of drowning}

A total of $28.1 \%$ of primary caregivers reported failing to provide full-time (which was defined as the caregiver having no permanent job and only looking after one child) care to the child, which may help explain why 43.3\% of children were alone (which was defined as the child being completely unsupervised) at the time of drowning (See Fig. 2). Smaller proportions of drowned children were accompanied by a primary caregiver

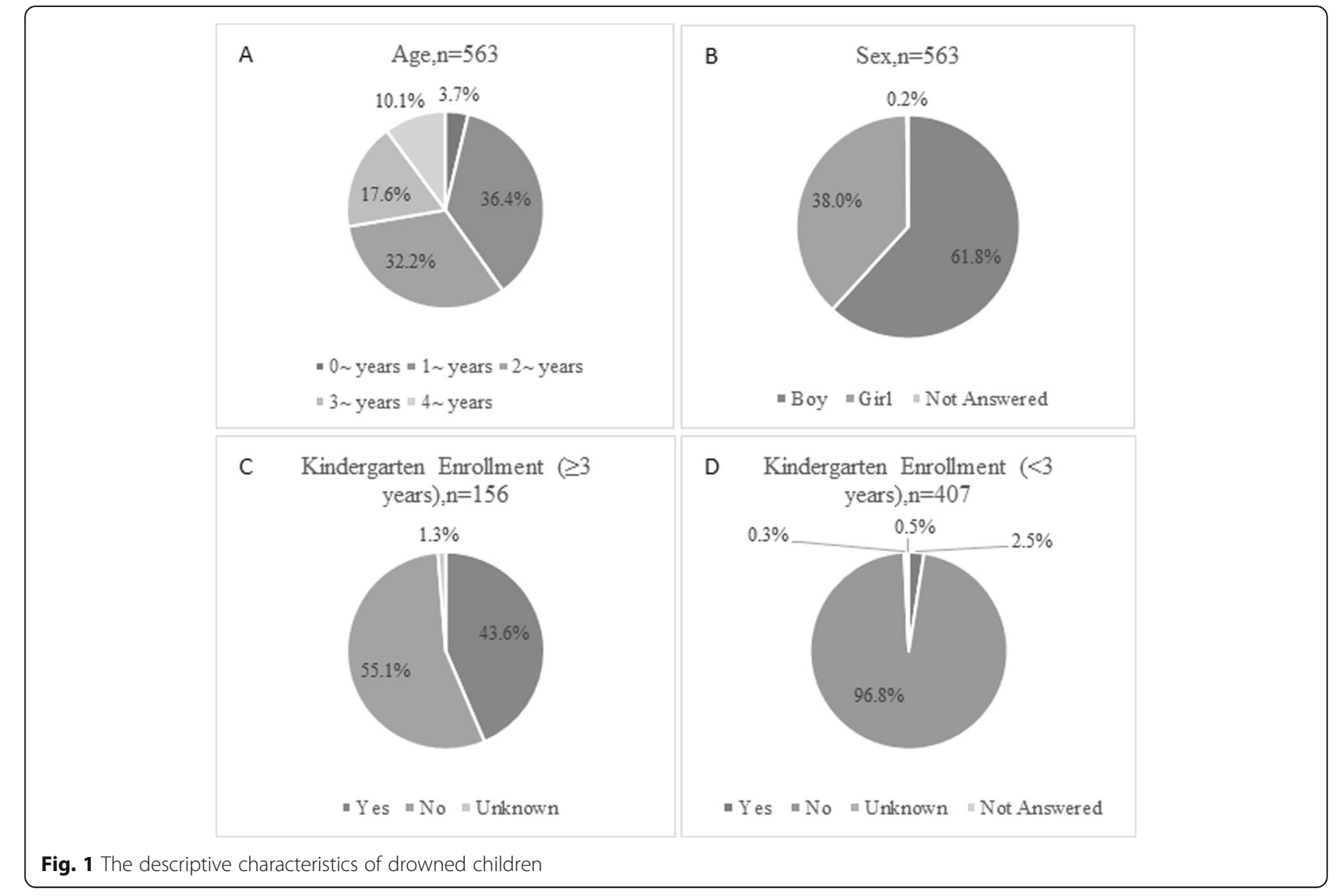


Table 1 Safety education status and activities of children under five in China

\begin{tabular}{ll}
\hline & $\mathbf{N}(\%)$ \\
\hline Accidental injury safety education $(\geq \mathbf{1}$ years), $\mathbf{N}=\mathbf{5 4 2}$ \\
Yes & $112(20.7)$ \\
No & $384(70.9)$ \\
Unknown & $23(4.2)$ \\
Not Answered & $23(4.2)$ \\
Playing near water body, $\mathbf{N = 5 6 3}$ & \\
Always & $20(3.6)$ \\
Sometimes & $311(55.2)$ \\
Never & $206(36.6)$ \\
Unknown & $21(3.7)$ \\
Not Answered & $5(0.9)$
\end{tabular}

Activities of children under 5 years old at the time of drowning, $\mathrm{N}=\mathbf{5 6 3}$

\begin{tabular}{ll} 
Playing near water body & $426(75.7)$ \\
Playing in water body & $26(4.6)$ \\
Slip during wading & $11(2.0)$ \\
Playing on the frozen river/lake & $3(0.5)$ \\
On the way to and from kindergarten & $2(0.4)$ \\
Bathing & $2(0.4)$ \\
Swimming & $1(0.2)$ \\
Other & $43(7.6)$ \\
Not Answered & $9(1.6)$ \\
Refused to Answer & $8(1.4)$ \\
Unknown & $32(5.7)$ \\
\hline
\end{tabular}

(21.9\%) or other children $(20.3 \%)$. Of the primary caregivers who were with the child at the time of drowning, only $12.8 \%$ were looking after the child; $47.9 \%$ were doing housework, and $20.2 \%$ were using the phone or socializing.

\section{Environmental characteristics of children under 5 who drowned in 334 districts in China \\ Locations and types of bodies of water}

Ponds, canals, rivers, and wells accounted for the most drowning locations $(80.8 \%)$, followed by home $(12.1 \%)$ (See Table 2). The results showed age differences between the drowning body of water with increasing age. The proportion of bathtub and water tank/bucket drownings decreased with age, and the proportion of pond, canal, river, and well drownings significantly increased with age.

A higher percentage of older children drowned away from home $(87.7 \%$ of $4 \sim$ year age group children vs. $47.6 \%$ of $0 \sim$ year age group children), and younger children were more likely to drown at home $(42.9 \%$ of $0 \sim$ year age group children vs. $5.3 \%$ of $4 \sim$ year age group children) (See Table 2).

\section{Environmental risk factors for drowning near children's residences}

The survey indicated that 403 drowned children (71.6\%) lived within $100 \mathrm{~m}$ of a body of water (See Fig. 3). Approximately $90 \%$ of these bodies of water were openly accessible without any fencing. For public bodies of water, $80.7 \%$ lacked any warning signs. For bodies of water located further than $100 \mathrm{~m}$ from the children's homes, only 8 of 563 could be completely covered to provide protection (See Table 3). Of the 62 bodies of

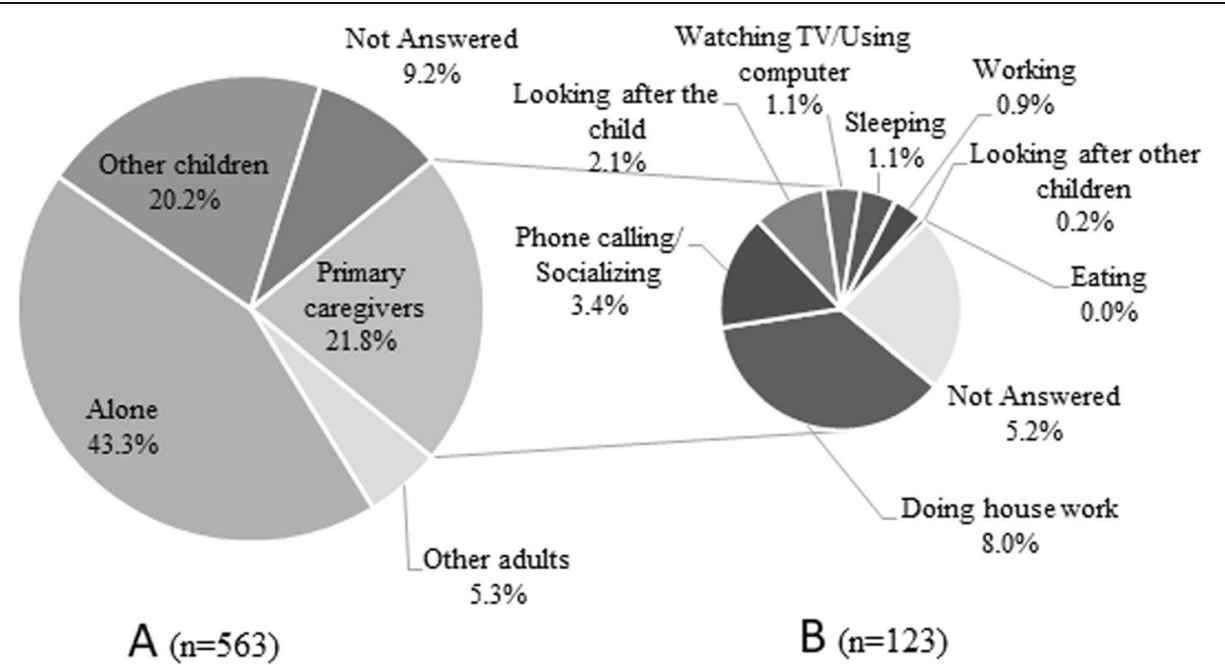

Fig. 2 Caregiver presence and engagement at the time of drowning of Chinese children under 5 years old. A) Who was present during the child's drowning. B) The behavior of the primary caregiver at the time of the child's drowning 
Table 2 Location and type of water body involved in drowning of children under 5 years old in 334 districts in China, $\mathrm{n}(\%)$

\begin{tabular}{|c|c|c|c|c|c|c|}
\hline \multirow[t]{2}{*}{ Variable } & \multicolumn{5}{|l|}{ Age, year } & \multirow[t]{2}{*}{ Total } \\
\hline & $0 \sim$ & $1 \sim$ & $2 \sim$ & $3 \sim$ & $4 \sim$ & \\
\hline \multicolumn{7}{|l|}{ Location of drowning } \\
\hline Ponds, canals, rivers, wells & $10(47.6)$ & $164(80.0)$ & $148(81.8)$ & $83(83.8)$ & $50(87.7)$ & $455(80.8)$ \\
\hline Home & $9(42.9)$ & $29(14.2)$ & $14(7.7)$ & $13(13.1)$ & $3(5.3)$ & $68(12.1)$ \\
\hline Farm (excluding home) & $0(0.0)$ & $3(1.5)$ & $5(2.8)$ & $1(1.0)$ & $1(1.8)$ & $10(1.8)$ \\
\hline Factory or construction site & $1(4.8)$ & $0(0.0)$ & $2(1.1)$ & $1(1.0)$ & $0(0.0)$ & $4(0.7)$ \\
\hline School (including kindergarten) & $0(0.0)$ & $0(0.0)$ & $1(0.6)$ & $0(0.0)$ & $0(0.0)$ & $1(0.2)$ \\
\hline Sport place & $0(0.0)$ & $0(0.0)$ & $0(0.0)$ & $0(0.0)$ & $1(1.8)$ & $1(0.2)$ \\
\hline Traffic place (such as station/ferry/pier) & $0(0.0)$ & $0(0.0)$ & $1(0.6)$ & $0(0.0)$ & $0(0.0)$ & $1(0.2)$ \\
\hline Other & $0(0.0)$ & $7(3.4)$ & $9(5.0)$ & $0(0.0)$ & $2(3.5)$ & $18(3.2)$ \\
\hline Not Answered & $1(4.8)$ & $1(0.5)$ & $0(0.0)$ & $1(1.0)$ & $0(0.0)$ & $3(0.5)$ \\
\hline Unknown & $0(0.0)$ & $1(0.5)$ & $1(0.6)$ & $0(0.0)$ & $0(0.0)$ & $2(0.4)$ \\
\hline Total & $21(100.0)$ & $205(100.0)$ & $181(100.0)$ & $99(100.0)$ & $57(100.0)$ & $563(100.0)$ \\
\hline \multicolumn{7}{|l|}{ Type of water body } \\
\hline Ditch & $6(28.6)$ & $66(32.2)$ & $44(24.3)$ & $31(31.3)$ & $11(19.3)$ & $158(28.1)$ \\
\hline Pool (fishpond) & $4(19.1)$ & $56(27.3)$ & $42(23.2)$ & $25(25.3)$ & $15(26.3)$ & $142(25.2)$ \\
\hline River /lake/sea & $2(9.5)$ & $12(5.9)$ & 34 (18.8) & $18(18.2)$ & 18 (31.6) & $84(14.9)$ \\
\hline Reservoir & $0(0.0)$ & $15(7.3)$ & $18(9.9)$ & $9(9.1)$ & $7(12.3)$ & $49(8.7)$ \\
\hline Well & $0(0.0)$ & $6(2.9)$ & $13(7.2)$ & $5(5.1)$ & $0(0.0)$ & $24(4.3)$ \\
\hline Water tank/bucket & $3(14.3)$ & $13(6.3)$ & $2(1.1)$ & $0(0.0)$ & $0(0.0)$ & $18(3.2)$ \\
\hline Open cesspool & $2(9.5)$ & $4(2.0)$ & $5(2.8)$ & $3(3.0)$ & $2(3.5)$ & $16(2.8)$ \\
\hline Bathtub & $1(4.8)$ & $4(2.0)$ & $1(0.6)$ & $0(0.0)$ & $0(0.0)$ & $6(1.1)$ \\
\hline Swimming pool & $0(0.0)$ & $0(0.0)$ & $0(0.0)$ & $0(0.0)$ & $1(1.8)$ & $1(0.2)$ \\
\hline Other (such as washing machine and boilers) & $1(4.8)$ & $21(10.2)$ & $21(11.6)$ & $7(7.1)$ & $3(5.3)$ & $53(9.4)$ \\
\hline Not Answered & $2(9.5)$ & $7(3.4)$ & $1(0.6)$ & $0(0.0)$ & $0(0.0)$ & $10(1.8)$ \\
\hline Unknown & $0(0.0)$ & $1(0.5)$ & $0(0.0)$ & $1(1.0)$ & $0(0.0)$ & $2(0.4)$ \\
\hline Total & $21(100.0)$ & $205(100.0)$ & $181(100.0)$ & $99(100.0)$ & $57(100.0)$ & $563(100.0)$ \\
\hline
\end{tabular}

water that had warning signs, the signs were difficult to see at more than half of the sites.

\section{Environmental risk factors for drowning at home}

Water containers were stored in the family homes of 234 (41.6\%) drowned children (See Fig. 4). Of these containers, $56.4 \%$ always stored water, $31.2 \%$ occasionally stored water, and fewer than $12 \%$ never stored water. No safety measures, such as fences, were implemented around approximately half (46.6\%) of these water containers.

\section{Discussion}

The present study suggests the following characteristics in the drowning of Chinese children under 5 years. First, children aged 1 to 2 years old and older children who are not enrolled in kindergarten were more likely to drown. Second, most children older than 1 year old had not received any accidental injury safety education (accounted for 70.9\%), and most primary caregivers (accounted for $83.1 \%$ ) had not received first aid training in drowning. Third, children typically drowned in bodies of water within $100 \mathrm{~m}$ of their home. Younger children tended to drown at home, and older children were more likely to drown outside the home in ponds, rivers, and canals. This difference is most likely due to the mobility of older children. The children in most drowning cases were playing next to the body of water and not in the water. Fourth, safety measures were markedly lacking in most drowning cases. Finally, most drowned children had caregivers who were less educated. Caregivers were attending to other chores and not minding the child when many drownings occurred, and nearly half of all children were alone when they drowned. These findings, in combination with a previous study in Hunan Province [19], indicate that full-time caregivers, accidental injury safety training, and water safety measures are important for drowning prevention. 


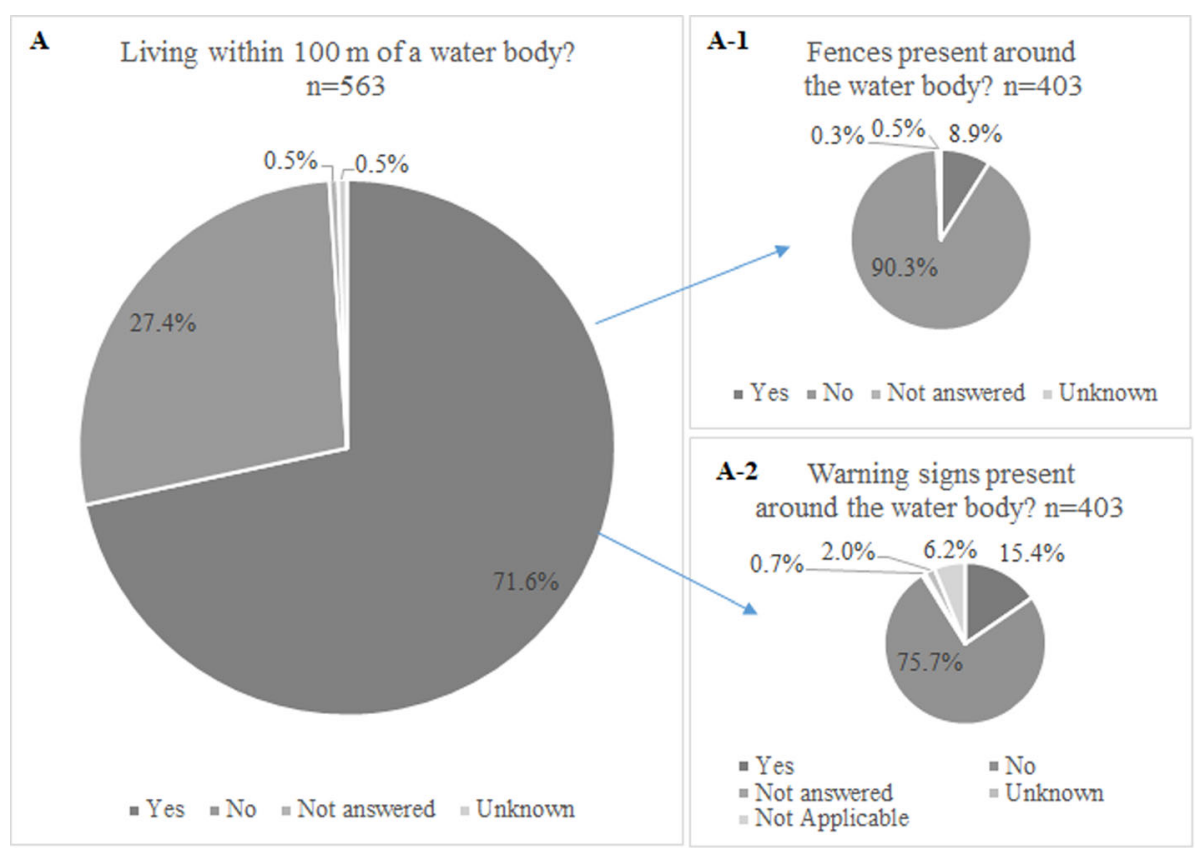

Fig. 3 Characteristics of bodies of water within $100 \mathrm{~m}$ of the homes of drowned children under 5 years in China

Table 3 Safety precautions for bodies of water in China where a child under 5 years old drowned

\begin{tabular}{ll}
\hline Safety precaution & $\mathbf{N}(\%)$ \\
\hline Presence of fence (except river /lake/sea), $\mathbf{N = 4 7 9}$ & \\
Yes & $23(4.8)$ \\
No & $442(92.3)$ \\
Not Answered & $7(1.5)$ \\
Unknown & $7(1.5)$ \\
Covered, N = 563 & \\
Uncovered & $314(55.8)$ \\
Cannot be covered & $210(37.3)$ \\
Covered partly & $18(3.2)$ \\
Completely covered & $8(1.4)$ \\
Other & $1(0.2)$ \\
Not Answered & $10(1.8)$ \\
Unknown & $2(0.4)$ \\
Warning signs (public bodies of water), N=563 & \\
Yes, the signs are easy to notice & $28(5.0)$ \\
Yes, the signs are not easy to notice & $34(6.0)$ \\
No & $465(82.6)$ \\
Not Answered & $13(2.3)$ \\
Unknown & $23(4.1)$ \\
\hline
\end{tabular}

The present study found that a great many drowned children lived within $100 \mathrm{~m}$ of the body of water, and most of these bodies of water had no fences. Most public bodies of water lacked warning signs. For the public bodies of water with warning signs, half of the warning signs were not easy to notice. Since most accidental drownings occurred at ponds, canals, rivers, and wells, the incompletion of safety measures in the living environment is an important risk factor for accidental drowning in children. Therefore, physical prevention measures in parallel with drowning prevention education are needed. Our study underscores the urgent need for fences and visible warning signs around bodies of water. Local governments should be encouraged to enact regulations and policies requiring that warning signs and protective barriers be installed near public bodies of water.

One major insight from the results of this study is the role of the primary caregivers. The results suggest that primary caregivers' education level and the level of mindfulness strongly affect the risks of child drowning. Primary caregivers in our survey were paying full attention to the child in only $12.8 \%$ of drowning cases when the primary caregiver was present. This result indicates a lapse in supervision among most caregivers.

A study in Australia showed that inadequate care and lapses in supervision, such as indoor housework, outdoor housework, and talking/socializing, were major contributors to child drowning [20]. We also found that caregivers were occupied with housework, phone calls or 


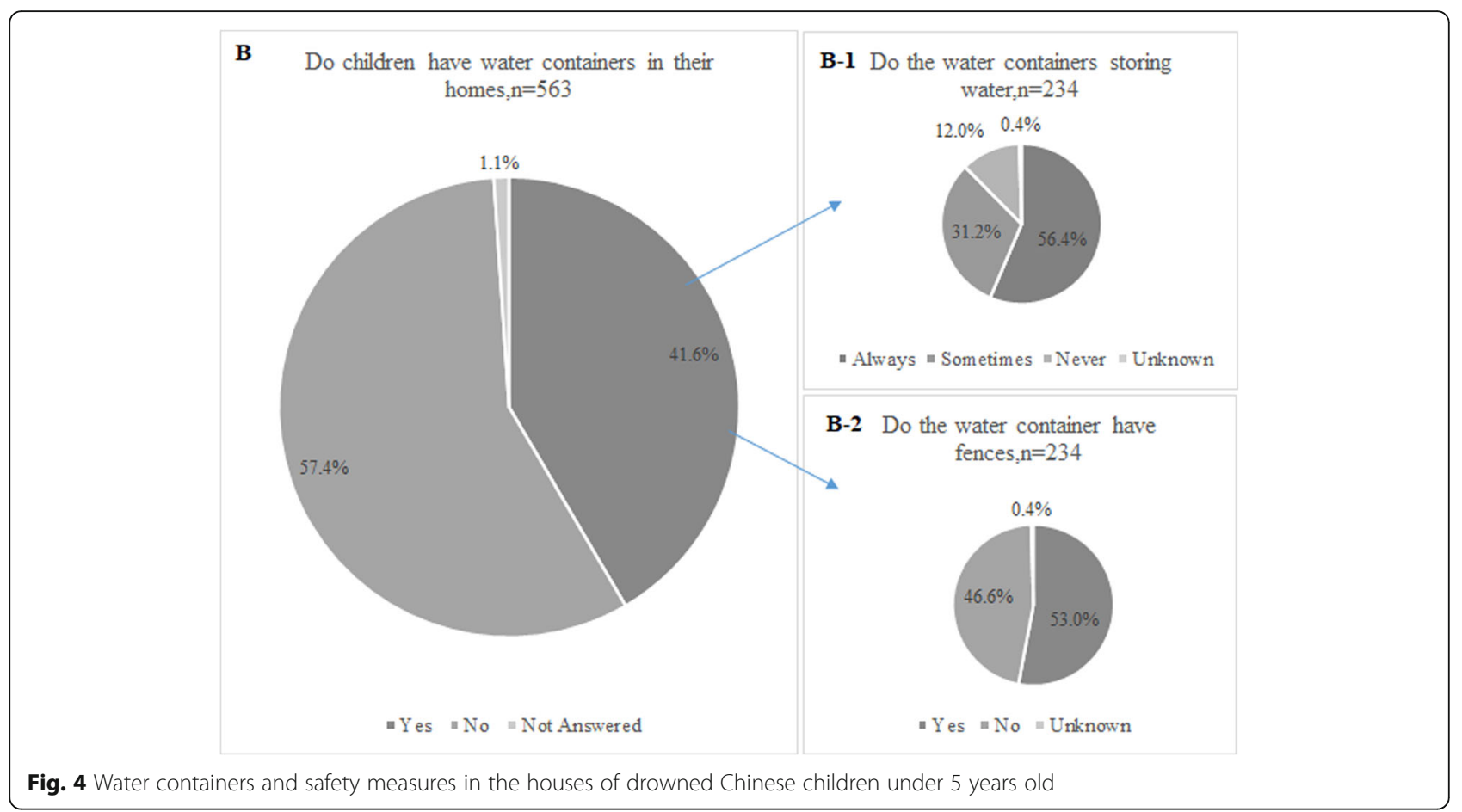

socializing at the time of the drowning. An Australiabased study of the accidental drowning of children from 0 to 17 years old between 2002 and 2014 found that all children who drowned had a lapse in supervision, and common supervision lapses were due to indoor household duties, outdoor household duties and talking/socializing [21]. Therefore, it is important to help primary caregivers understand the consequence of supervision lapses. Local communities can promote the benefits of full-time parental care within their jurisdictions and use health education programs to help parents learn about child drowning prevention and first aid information for drowning. Sending injury prevention knowledge via SMS or voice messages to parents' mobile phones may effectively raise awareness and reduce the risk of drowning, as suggested by a study in Bangladesh [22]. These strategies were effective in the Jiangsu province in China, where parental awareness of, and behaviors to prevent, accidental suffocation and drowning in rural children changed significantly after the enacting of health education programs [23].

Raising awareness of drowning prevention may also prove beneficial when it is provided to the caregivers and the children. One way to increase awareness of kindergarten-aged children would be for the local government to strengthen safety education training in the classroom and encourage kindergarten enrollment because we found that over half of drowned children were not enrolled in kindergarten despite being of kindergarten age.
We propose teaching children to avoid unprotected bodies of water to help reduce the drowning mortality rate. As children become older, more mobile and independent, emphasis should be shifted from safety around water containers in the home to safety around open bodies of water outdoors. Moreover, prevention programs should reinforce that a child should always seek adult supervision when playing in and around bodies of water. To be most effective, these prevention programs should be age-appropriate.

\section{Conclusions}

To our knowledge, the present study is the most extensive survey of the characteristics of drowning deaths of children under 5 years in China. These data suggest several key risk factors that may help guide the design and improvement of child drowning prevention programs.

\section{Abbreviations}

AUD: Australian Dollar; NMCHSS: the National Maternal and Child Health Surveillance System; UNICEF: the United Nations Children's Fund; SMS: Short Message Service

\section{Acknowledgments}

We thank the institutions and staff of the National Maternal and Child Health Surveillance System for the data collection.

\section{Authors' contributions}

Surveys were performed by $H L, Y W$, and LK. MW and YL performed data analyses using software optimized by $\mathrm{CH}, \mathrm{LK}$, and QL. JZ, JL, LM, JH, and XH curated the data. The manuscript was written by MW and reviewed and edited by MW, YL, HL, and YW. All authors have read and approved the manuscript. 


\section{Funding}

This work was funded by the Department of Women and Children of the National Health Commission of China, UNICEF, and the Sichuan Science and Technology Department Project (No.2018ZR0334). The funders were involved in designing the study but were not involved in the collection, analysis, or interpretation of the data, or writing of the manuscript.

\section{Availability of data and materials}

This study used data from the NMCHSS. This system was coestablished by the National Health and Family Planning Commission of the People Republic of China and Sichuan University, and it is owned by the National Health and Family Planning Commission of the People Republic of China. The researchers did not obtain consent to publicly share the data. The deidentified data set is available upon request to interested researchers. For data requests, please contact the Department of Science and Technology of West China Second University Hospital, Sichuan University, at: fu2 yuankjb@163.com. This department is in charge of all programs in the hospital, including data management. One staff member from the department (named Xian He) monitors this email address.

\section{Ethics approval and consent to participate}

The Ethics Committee of West China Second University Hospital, Sichuan University, China, approved this study. All respondents provided verbal informed consent for their anonymized responses to be analyzed and published. The ethics committee approved this method of obtaining verbal consent.

\section{Consent for publication}

Not applicable.

\section{Competing interests}

The authors declare that they have no competing interests.

\section{Author details}

${ }^{1}$ Key Laboratory of Birth Defects and Related Diseases of Women and Children (Sichuan University), Ministry of Education, West China Second University Hospital, Chengdu, China. ${ }^{2}$ National Office for Maternal and Child Health Surveillance of China, West China Second University Hospital, Sichuan University, Chengdu, Sichuan, China. ${ }^{3}$ Meishan Maternal and Child Health Care Hospital, Meishan, Sichuan, China. ${ }^{4}$ Chengdu Qingyang Maternal and Child Health and Family Planning Service Center, Chengdu, Sichuan, China. ${ }^{5}$ Department of Pediatrics, West China Second University Hospital, Sichuan University, Chengdu, China.

Received: 30 March 2020 Accepted: 7 October 2020

Published online: 15 October 2020

\section{References}

1. World Health Organization. Global report on drowning: preventing a leading killer. Geneva: World Health Organisation; 2014

2. Suominen PK, Vähätalo R. Neurologic long term outcome after drowning in children. Scand J Trauma Resusc Emerg Med. 2012;20:55.

3. Hughes SK, Nilsson DE, Boyer RS, Bolte RG, Hoffman RO, Lewine JD, Bigler ED. Neurodevelopmental outcome for extended cold water drowning: a longitudinal case study. J Int Neuropsychol Soc. 2002;8(4):588-95.

4. Mott TF, Latimer KM. Prevention and treatment of drowning. Am Fam Physician. 2016 Apr 1;93(7):576-82.

5. Lozano R, Naghavi M, Foreman K, Lim S, Shibuya K, Aboyans V, et al. Global and regional mortality from 235 causes of death for 20 age groups in 1990 and 2010: a systematic analysis for the global burden of disease study 2010. Lancet. 2012 Dec 15;380(9859):2095-128.

6. Royal life saving national drowning report 2018. https://www.royallifesaving. com.au/facts-and-figures/research-and-reports/drowning-reports. Accessed 10 Oct 2020

7. WHO. World Report on Child Injury Prevention. Geneva: WHO; 2008. p. 6-7

8. The General Office of the National Health and Family Planning Commission. Health Literacy of Chinese Citizens -- Basic Knowledge and Skills. 2015

9. Xiongcun Town People Government of She County. Notice on prevention of drowning among teenagers and children in 2019, 2019.

10. Luoling Town Government of Yixiu District, Notice on prevention of drowning among teenagers and children in 2019, 2019.
11. Bozhou City Education Bureau, Notice on Further Publicity and Education on the Prevention of Drowning among Adolescents and Children. 2017.

12. Zhou J, Yi ZS. Analysis on mortality and causes of death in children under 5 years old from 2006 to 2013. Chin J Mater Child Health. 2014;5(6):60-3.

13. Ning ST, Wang ZY, Si H, Wang HW, Zhao H, Wang M. The relationship between student traffic accident and drowning risk behavior and their Mother's educational level. Public Health Manag Chin. 2014;30(6):860-2.

14. Yang HB, Dong JQ. Analysis on the current situation and trend of the death of children under five years old in Wuxi from 2009 to 2013. Chin Mater Child Health Care. 2015;30(07):1091-2.

15. Song $P, F u ~ D, Z$ Zhang JS, Lin SQ, Xu H. Trends and interventions in accidental deaths of children under five years old. Application Modern Med Chin. 2015;9(09):272-4.

16. Liu W, Jia SJ. Levels and trends of injury mortality among children aged 114 in China from 2002 to 2011. Chin J Child Health. 2014:22(10):1095-8.

17. Gu YJ. Analysis on causes of accidental death and intervention of children under 5 years old from 2010 to 2015 in Wuxi. China Mater Child Health Care. 2018:33(15):3365-9.

18. He C, Liu L, Chu Y, Perin J, Dai L, Li XH, et al. National and subnational allcause and cause-specific child mortality in China, 1996-2015: a systematic analysis with implications for the sustainable development goals. Lancet Glob Health. 2016;2(5):186-97.

19. Liu Z, Kong F, Yin L, Wang A, Xiong L, Xie D, Chen L, Sheng X. Epidemiological characteristics and influencing factors of fatal drowning in children under 5 years old in Hunan Province, China: case-control study. BMC Public Health. 2019:19(1):955.

20. Chang SSM, Ozanne-Smith J.Drowning mortality in children aged 0-14 years in Victoria, Australia: detailed epidemiological study 2001-2016 Injury Prevention Published Online First: 2019. https://doi.org/10.1136/injuryprev2019-043307.

21. Peden Amy E, Franklin Richard C. Causes of distraction leading to supervision lapses in cases of fatal drowning of children 0-4 years in Australia: A 15-year review. J Paediatr Child Health. 2019;56(3).

22. Mosharaf H, Mani Kulanthayan KC, Sherina MS, Hayati KS. The development of an intervention package to prevent children under five years old drowning in rural Bangladesh. Acta Paediatrica. 2016;105(8):e373-8.

23. Zhang PB, Chen RH, Deng JY, Xu BR, Hu YF. Evaluation of health education on intervention effect of accidental suffocation and drowning in rural children aged $0 \sim 4$ years. Chin J Pediatr. 2003;07:21-4.

\section{Publisher's Note}

Springer Nature remains neutral with regard to jurisdictional claims in published maps and institutional affiliations.

Ready to submit your research? Choose BMC and benefit from:

- fast, convenient online submission

- thorough peer review by experienced researchers in your field

- rapid publication on acceptance

- support for research data, including large and complex data types

- gold Open Access which fosters wider collaboration and increased citations

- maximum visibility for your research: over $100 \mathrm{M}$ website views per year

At $\mathrm{BMC}$, research is always in progress.

Learn more biomedcentral.com/submissions 